\title{
EFEITOS DE UM AMBIENTE VIRTUAL E DO TIPO DE CONSEQUÊNCIAS SOBRE A APRENDIZAGEM DE
} DISCRIMINAÇÕES SIMPLES EM PRÉ-ESCOLARES

\author{
EFFECTS OF A VIRTUAL ENVIRONMENT AND TYPE OF CONSEQUENCES ON SIMPLE DISCRIMINATION \\ LEARNING BY PRESCHOOLERS
}

\author{
VANESSA AYRES PEREIRA \\ UNIVERSIDADE FEDERAL DE SÃo CARLOS, BRASIL E \\ INSTITUTO NACIONAL DE CIÊNCIA E TECNOLOGIA SOBRE COMPORTAMENTO COGNIÇÃo E ENSINO, BRASIL
}

\author{
DANIELA DE SOUZA CANOVAS \\ UNIVERSIDADE DE SÃO PAULO, BRASIL E \\ INSTITUTO NACIONAL DE CIÊNCIA E TECNOLOGIA SOBRE COMPORTAMENTO COGNIÇÃo E ENSINO, BRASIL
}

\author{
DEISY DAS GRAÇAS DE SOUZA \\ UNIVERSIDADE FEDERAL DE SÃo CARLOS, BRASIL E \\ INSTITUTO NACIONAL DE CIÊNCIA E TECNOLOGIA SOBRE COMPORTAMENTO COGNIÇÃo E ENSINO, BRASIL
}

\begin{abstract}
RESUMO
Este estudo avaliou os efeitos de um ambiente virtual e do tipo de consequência para acertos, sobre o processo de aprendizagem e a reversão de discriminações simples visuais, e sobre a manutenção de pré-escolares em situação experimental. $\mathrm{O}$ ambiente virtual era um cenário dinâmico apresentado na tela do computador, que simulava uma floresta com árvores sobre as quais eram posicionados os estímulos. Os experimentos 1 e 2 compararam os efeitos das condições A e B. Ambas empregaram o ambiente virtual, porém, como consequência para cada resposta correta, na Condição A eram exibidos trechos de vídeos de desenhos animados, e na Condição $\mathrm{B}$, uma breve animação de estrelas coloridas com sons. Os resultados dos experimentos apontaram que o emprego de vídeos produziu menos erros e manteve as crianças engajadas em situação experimental. O Experimento 3 comparou os efeitos das condições A e C. Ambas empregaram vídeos como consequências para acertos; porém, na Condição A o cenário era o ambiente virtual, e na Condição $\mathrm{C}$, um fundo branco e estático. Os resultados indicaram que os cenários não tiveram efeitos diferenciais sobre as variáveis consideradas dependentes. Em conjunto, os resultados indicaram que os tipos de consequências foram mais determinantes da aprendizagem do que o emprego do ambiente virtual.
\end{abstract}

Palavras-chave: ambiente virtual, reforço, discriminação simples, reversão de discriminação, crianças.

The present study evaluated the effects of a virtual environment and the type of consequences for correct responses, on learning process of visual simple discriminations and reversals, and on the maintenance of preschool children in experimental situation. The virtual environment was a dynamic scenario presented on the computer screen, which simulated a forest with trees, on which the stimuli were presented. Experiments 1 and 2 compared the effects of Conditions A and B. Both conditions used the virtual environment, however, the consequence for correct responses were cartoon videos in Condition A, and an auditory visual animation with stars in Condition B. The results indicated that using videos as consequences for correct responses produced errorless and maintained children committed in experimental situation. Experiment 3 compared effects of Conditions A and C. Both conditions used videos as consequences for correct responses; however, in Condition A the scenario was the virtual environment, while in Condition $\mathrm{C}$ it was a white static background. The results indicated that the scenarios did not produced differential effects on variables considered dependents. Together, the results indicated that the type of consequences were more decisive on producing learning than the virtual environment.

Keywords: virtual environment, reinforcement, simple discrimination, discrimination reversal, children.

\footnotetext{
Vanessa A. Pereira, Daniela S. Canovas e Deisy G. de Souza são membros do Instituto Nacional de Ciência e Tecnologia sobre Comportamento, Cognição e Ensino (INCT-ECCE), financiado pelo CNPq (Processo \#573972/2008-7) e pela FAPESP (Processo \#2008/57705-8), que apoiou a redação do manuscrito. A condução da pesquisa foi apoiada por bolsas da FAPESP: Iniciação Científica para a primeira autora (Processo \#2011/0646-6) e Mestrado para a segunda (Processo \#2010/06422-6). As autoras agradecem a Carlos de Sousa Brito Neto, Manoel Ribeiro Filho e Olavo de Faria Galvão, da UFPA, pela autorização de uso do software de sua autoria para a condução do procedimento experimental. Agradecem também a dois revisores anônimos pela leitura cuidadosa e pelas sugestões que contribuíram para aprimorar a versão final deste artigo. Correspondência editorial para vanessa.ayresp@ gmail.com
} 
Estudos com crianças pequenas exigem certos aspectos de metodologia específicos que incluem o arranjo da situação experimental para garantir um ambiente motivador capaz de manter as crianças em situação experimental e também o responder sob o controle dos estímulos relevantes. Crianças possuem menor história de aprendizagem e, por isso, em investigações sobre as variáveis que controlam o comportamento humano, estudos com populações infantis são considerados relevantes, pois produzem maior controle experimental (Oliveira \& Gil, 2008; Pilgrim, 1998). No Brasil, particularmente uma equipe de pesquisadores, liderada por Gil, tem investigado procedimentos específicos e eficazes para ensinar e manter crianças pequenas em ambiente controlado (e.g. Gil, Oliveira, \& McIlvane, 2011; Gil, Oliveira, Sousa, \& Faleiros, 2006; Oliveira et al., 2008).

A apresentação de consequências reforçadoras contingentemente às respostas é um aspecto essencial em um procedimento para produzir aprendizagem. Para manter as crianças em situação experimental e produzir respostas em relação à tarefa, estudos com crianças tem empregado estratégias e reforçadores variados. Por exemplo, algumas investigações sobre processos básicos de aprendizagem com crianças empregaram consequências naturais como reforçadores - como a oportunidade de manipulação do estímulo, quando a criança escolhe o estímulo definido como correto em uma tarefa de discriminação, associada à oportunidade de interagir ludicamente com o experimentador (e.g. Gil et al., 2011; Gil et al., 2006; Oliveira et al., 2008).

Também é relatado na literatura o emprego de reforçadores condicionados como consequências imediatas para respostas corretas, por exemplo, uma animação breve na tela do computador e fichas que, ao final da sessão, são trocadas pela apresentação atrasada de reforçadores variados, extrínsecos à tarefa, como brinquedos, itens de papelaria, adesivos, acesso à brincadeira, entre outros (e.g., Canovas, de Souza, \& Barros, 2013; LionelloDeNolf, McIlvane, Canovas, de Souza, \& Barros, 2008; Pilgrim, Click, \& Galizio, 2011; Postalli, Canovas, \& de Souza, 2015).

Tanto alguns dos estudos que empregaram consequências naturais, quanto alguns dos que empregaram consequências arbitrárias, relataram variabilidade entre sujeitos ou dificuldade em produzir aprendizagem e manter as crianças respondendo à tarefa experimental (Canovas et al., 2013; Gil et al., 2011; Gil et al., 2006; Lionello-DeNolf et al., 2008; Postalli et al., 2015). Por isso, com o objetivo de produzir aprimoramento metodológico, seria importante investigar outros procedimentos de ensino, potencialmente eficazes, que envolvam a apresentação imediata de consequências reforçadoras, particularmente, consequências intrínsecas ou mais relacionadas à natureza da atividade realizada pelas crianças (diferentes do uso de fichas e acesso a brinquedos e itens).

Considerando que o objetivo final dos estudos também é produzir tecnologia de ensino, que possa ser utilizada em contexto aplicado, o desenvolvimento de procedimentos que impliquem no uso de consequências intrínsecas ou diretamente produzidas no contexto da atividade são importantes porque podem ser apresentados, por exemplo, por pais e professores, sem a presença de um experimentador e sem a necessidade de planejamento de reforçadores adicionais e atrasados.

Vários autores utilizaram tarefas em ambiente virtual em procedimentos experimentais com crianças e relataram que as atividades funcionaram como reforçadores positivos, favorecendo a emissão de respostas em relação à tarefa (e.g. Fogel, Miltenberger, Graves, \& Koehler, 2010; Monteiro, 2011; Tüzun, Yilmaz-Soylu, Karakus, Inal, \& Kizilkaya, 2008). Alguns autores consideram que a estimulação multissensorial e a oportunidade de emitir diferentes respostas que produzam consequências diversas seriam aspectos que colaborariam para o aumento da complexidade da experiência e do engajamento dos participantes em relação à tarefa (Garris, Ahlers, \& Driskell, 2002). Outros autores atribuem parte do valor reforçador dos ambientes virtuais, comumente apresentados em jogos eletrônicos, à sua importância nos processos de socialização das novas gerações (Belloni \& Gomes, 2008). Seja pelo caráter lúdico e suposto valor reforçador natural que segue a resolução da tarefa (Garris, et al., 2002) ou pelo valor reforçador condicionado (Belloni et al., 2008), os ambientes virtuais são apontados como potencialmente capazes de produzir efeitos sobre a aprendizagem.

Os ambientes virtuais são representações gráficas de um cenário e/ou objeto em duas dimensões que, a partir do tratamento da imagem por meio de técnicas de computação gráfica, produzem a impressão de profundidade. A representação pode ser estática ou dinâmica, comumente inclui a estimulação multissensorial (e.g., visual, auditiva, etc.) e pode ser reproduzida, por exemplo, por monitores ou capacetes de visualização. Sistemas de realidade virtual permitem que ações de um usuário operem modificações instantâneas em ambiente virtual pela utilização de dispositivos convencionais, como mouse e teclado, ou mais sofisticados, como luvas e sensores de movimento e de voz (Burdea \& Coiffet, 1994; Monteiro, 2011).

Devido à relevância de se desenvolver procedimentos adequados a populações infantis, Pereira, Canovas, de Souza, Brito Neto e Galvão (2010) conduziram uma investigação sobre a viabilidade da utilização de um procedimento em ambiente virtual para ensinar discriminações simples e simultâneas para crianças pré-escolares e para mantê-las engajadas em situação experimental sem o uso de reforçadores extrínsecos à tarefa. Discriminação simples é o processo pelo qual o sujeito passa a responder diferencialmente a dois ou mais estímulos apresentados simultaneamente, em função da consequência produzida pelo comportamento (Catania, 1999). Pereira et al. (2010) utilizaram um software, desenvolvido por Brito Neto, Ribeiro Filho e Galvão (2008), para ensinar discriminações visuais, simples e simultâneas, a quatro crianças com desenvolvimento típico e idades entre quatro e cinco anos. A tarefa era apresentada na tela do computador, em um ambiente virtual composto por estímulos familiares (figuras de 
frutas), tridimensionais e estáticos, apresentados sobre um cenário tridimensional e dinâmico que representava um ambiente similar a uma floresta. A seleção das figuras definidas como corretas era consequenciada com a movimentação do cenário até a representação de uma televisão, onde era exibido um trecho de um episódio de desenho animado escolhido pela criança antes do início da sessão experimental. Os resultados mostraram que os quatro participantes se mantiveram engajados na situação experimental e aprenderam as discriminações rapidamente. Todavia, os autores identificaram a necessidade de pesquisas subsequentes para investigar quais aspectos da tarefa funcionaram como reforçadores e produziram as respostas de interesse: a apresentação constante do ambiente virtual ao longo da tarefa ou a apresentação contingente de vídeos de desenhos animados às respostas corretas.

Dando continuidade a essa linha de investigação, foram conduzidos os três experimentos relatados neste artigo. Nos experimentos 1 e 2, a variável manipulada foi a consequência supostamente reforçadora e no Experimento 3, o tipo de cenário de ensino da tarefa, se ambiente virtual ou cenário branco e estático. Nos três experimentos, foram avaliados os efeitos dessas variáveis sobre o processo de aprendizagem das discriminações e sobre a manutenção dos comportamentos requeridos pela tarefa experimental.

\section{EXPERIMENTO 1}

O objetivo do Experimento 1 foi identificar se, em uma tarefa em ambiente virtual, o tipo de consequência seria uma variável crítica ou não para manter as crianças na situação experimental e para produzir efeitos sobre o processo de aprendizagem das discriminações. Os efeitos diferenciais de cada condição foram medidos em termos de número de acertos e número de erros até que a criança apresentasse um desempenho preciso nas tarefas discriminativas.

\section{Participantes}

\section{MÉTODO}

Os participantes foram quatro meninos e quatro meninas (P1, P2, P3, P4, P5, P6, P7 e P8), com idades entre quatro anos e um mês e cinco anos e sete meses $(\mathrm{M}=5,2$ anos), experimentalmente ingênuos e frequentadores de uma creche no interior do estado de São Paulo. Todos apresentaram desenvolvimento global considerado normal de acordo com avaliações por meio do instrumento de triagem Denver II (Pedromônico, Bargatto \& Strobilus, 1999), exceto P2 que não foi avaliada por se recusar a realizar vários itens do teste. De acordo com avaliações por meio do PPVT-R (Dunn \& Dunn, 1981), cinco participantes (P4, P5, P6, P7 e P8) apresentaram repertório verbal receptivo superior ao esperado para a idade cronológica, um participante (P3) apresentou o repertório esperado e dois (P1 e P2) apresentaram repertórios inferiores aos esperados (ver Tabela 1). O repertório verbal receptivo é avaliado por meio do desempenho em tarefas de discriminação auditivo-visuais (selecionar uma figura diante da palavra falada correspondente). O projeto foi aprovado pelo Comitê de
Ética em Pesquisa da UFSCar (Protocolo CAAE 0169.0.135.000-09).

\section{Situação experimental, Equipamentos e Materiais}

Em uma sala foi instalado um computador PC acoplado a um monitor CRT de 14 polegadas. Cada participante era convidado para "jogar" no computador e, após seu consentimento, era levado individualmente até a sala em que era realizada a sessão. As respostas de consentimento da criança para realizar a sessão eram registradas e utilizadas como medida de manutenção do participante em situação experimental. A tarefa da criança era posicionar o cursor (seta) sobre os estímulos apresentados na tela e apertar o botão esquerdo do mouse (resposta de "clicar"). O software desenvolvido por Brito Neto e colaboradores (2008) realizava a apresentação da tarefa em tentativas discretas (estímulos e consequências) e registrava as respostas de clicar. Após a conclusão de um bloco de tentativas, a experimentadora perguntava à criança se ela gostaria de "jogar" novamente. Ao longo de uma sessão experimental, as crianças podiam realizar até três blocos de tentativas, de acordo com a sua disposição e a disponibilidade de tempo.

\section{Estímulos}

Os estímulos empregados foram três figuras de flores (Conjunto $a$ : $a 1, a 2, a 3$ ) e três figuras de animais (Conjunto $b: b 1, b 2, b 3$ ). A Figura 1 representa os estímulos empregados neste experimento e nos experimentos subsequentes. No ambiente virtual, eram apresentados três exemplares iguais de cada estímulo, como ilustrado na Figura 2. Por exemplo, quando o $\mathrm{S}^{+}$ fosse o $a 1$, três exemplares da mesma flor eram apresentados em uma das árvores do cenário, enquanto outros três exemplares da flor $a 2$ eram apresentados em uma segunda árvore; e três exemplares da flor $a 3$ eram apresentados em uma terceira árvore.

\section{Procedimento}

As crianças foram expostas a duas condições experimentais (A e B). Ambas empregavam o mesmo ambiente virtual como cenário para tarefas de discriminação simples simultânea com estímulos visuais. As condições eram diferentes apenas em relação ao conjunto de estímulos empregados como discriminativos e às consequências contingentes às respostas diante de estímulos definidos como $\mathrm{S}^{+}$(respostas corretas). $\mathrm{Na}$ Condição A, eram apresentados simultaneamente os três estímulos do Conjunto $a$ e após cada resposta correta era apresentado, em ordem cronológica, um trecho diferente, com duração de $8 \mathrm{~s}$, de um episódio de desenho animado, escolhido pela criança antes de iniciar a sessão. $\mathrm{Na}$ Condição B eram apresentados os três estímulos do Conjunto $b$ e a cada resposta correta era apresentada uma mesma animação de estrelas coloridas acompanhadas de um som ascendente, com duração de 2 s (consequência similar à do software MTS desenvolvido por Dube, 1991; Dube \& Hiris, 1996). A cada tentativa um dos estímulos do conjunto funcionava como $\mathrm{S}^{+}$e os outros dois funcionavam como $\mathrm{S}^{-}$. 
Tabela 1. Características dos participantes dos Experimentos 1, 2 e 3: sexo, idade no início do procedimento, idade no PPVT (Dunn et al., 1981) e desempenho no instrumento Denver II (Pedromônico et al., 1999).

\begin{tabular}{|c|c|c|c|c|c|c|c|}
\hline $\begin{array}{l}\text { Experi- } \\
\text { mento }\end{array}$ & $\begin{array}{l}\text { Delinea- } \\
\text { mento }\end{array}$ & $\begin{array}{c}\text { Sequência de } \\
\text { apresentação } \\
\text { das Condições }\end{array}$ & $\begin{array}{l}\text { Partici- } \\
\text { pante }\end{array}$ & $\begin{array}{c}\text { Sexo } \\
(\mathbf{F} / \mathbf{M})\end{array}$ & $\begin{array}{c}\text { Idade } \\
(\mathbf{a}-\mathbf{m})\end{array}$ & $\begin{array}{c}\text { Idade } \\
\text { PPVT-R } \\
(\mathbf{a}-\mathbf{m})\end{array}$ & $\begin{array}{c}\text { Desempenho Denver } \\
\text { II }\end{array}$ \\
\hline 1 & $\begin{array}{l}\text { Blocos } \\
\text { alternados }\end{array}$ & $\begin{array}{c}\text { ABBABABAA } \\
\text { BBABABABA } \\
\text { ABBA }\end{array}$ & $\begin{array}{l}\text { P1 } \\
\text { P2 } \\
\text { P3 } \\
\text { P4 } \\
\text { P5 } \\
\text { P6 } \\
\text { P7 } \\
\text { P8 }\end{array}$ & $\begin{array}{c}\text { M } \\
F \\
M \\
M \\
M \\
F \\
F \\
F\end{array}$ & $\begin{array}{c}5-2 \\
5-5 \\
5-5 \\
5-7 \\
4-11 \\
5-2 \\
4-1 \\
5-5\end{array}$ & $\begin{array}{l}4-0 \\
5-3 \\
5-5 \\
9-7 \\
5-6 \\
6-6 \\
4-5 \\
5-8\end{array}$ & $\begin{array}{c}\text { Normal } \\
-{ }^{b} \\
\text { Normal } \\
\text { Normal } \\
\text { Normal } \\
\text { Normal } \\
\text { Normal } \\
\text { Normal }\end{array}$ \\
\hline & & $\mathrm{ABAB} A B \mathrm{AB}$ & $\begin{array}{l}\text { P9 } \\
\text { P10 } \\
\text { P11 }\end{array}$ & $\begin{array}{l}\mathrm{N} \\
\mathrm{F} \\
\mathrm{F}\end{array}$ & $\begin{array}{l}4-0 \\
4-0 \\
3-7\end{array}$ & $\begin{array}{l}6-6 \\
3-3 \\
3-5\end{array}$ & $\begin{array}{l}\text { Normal } \\
\text { Atraso } \\
\text { Normal }\end{array}$ \\
\hline 2 & $\begin{array}{l}\text { Medidas } \\
\text { Repetidas }\end{array}$ & BABABABA & $\begin{array}{l}\text { P12 } \\
\text { P13 } \\
\text { P14 }\end{array}$ & $\begin{array}{l}\mathrm{F} \\
\mathrm{M} \\
\mathrm{M}\end{array}$ & $\begin{array}{l}3-7 \\
4-1 \\
3-7\end{array}$ & $\begin{array}{c}2-7 \\
4-10 \\
4-3\end{array}$ & $\begin{array}{l}\text { Atraso } \\
\text { Normal } \\
\text { Normal }\end{array}$ \\
\hline 3 & $\begin{array}{l}\text { Medidas } \\
\text { Repetidas }\end{array}$ & CACACA & $\begin{array}{l}\text { P15 } \\
\text { P16 } \\
\text { P17 } \\
\text { P18 } \\
\text { P19 } \\
\text { P20 } \\
\text { P21 }\end{array}$ & $\begin{array}{c}\mathrm{M} \\
\mathrm{M} \\
\mathrm{F} \\
\mathrm{F} \\
\mathrm{F} \\
\mathrm{M} \\
\mathrm{F}\end{array}$ & $\begin{array}{l}3-7 \\
3-7 \\
3-6 \\
3-4 \\
3-6 \\
3-5 \\
3-8\end{array}$ & $\begin{array}{c}3-11 \\
3-8 \\
3-7 \\
3-10 \\
4-1 \\
4-4 \\
4-0\end{array}$ & $\begin{array}{l}\text { Normal } \\
\text { Normal } \\
\text { Normal } \\
\text { Normal } \\
\text { Normal } \\
\text { Normal } \\
\text { Normal }\end{array}$ \\
\hline
\end{tabular}

${ }^{\text {a }}$ A participante se recusou a realizar vários itens do teste.

Estrutura dos blocos de tentativas em ambiente virtual.

Cada bloco era organizado em três tentativas (tentativas 1, 2 e 3) e uma tela de finalização, conforme ilustrado pela Figura 2. A cada tentativa eram apresentados simultaneamente os três estímulos do conjunto (um $\mathrm{S}^{+}$e dois $\mathrm{S}^{-}$), porém, para cada estímulo eram apresentados três exemplares idênticos. Isto significa que o participante podia apresentar até três respostas corretas em uma mesma tentativa, se ele selecionasse exclusivamente o $\mathrm{S}^{+}$; o número total de respostas podia variar em função da quantidade de escolhas de um exemplar de $\mathrm{S}^{-}$.

$\mathrm{Na}$ tentativa 1 , dois estímulos do conjunto eram apresentados em tamanho similar (três exemplares idênticos de um dos estímulos exerciam função de $\mathrm{S}^{+}$e três exemplares idênticos do outro estímulo, função de $\mathrm{S}^{-}$). Outros três exemplares idênticos, do terceiro estímulo do conjunto, também com função de $\mathrm{S}^{-}$, eram apresentados no centro da tela, em tamanho menor (ver Figura 2). Respostas aos $\mathrm{S}^{-}$em tamanho menor, assim como em relação ao cenário, não produziam consequências programadas e não eram registradas.
Respostas diante de um estímulo com função de $\mathrm{S}^{-}$de tamanho similar aos $\mathrm{S}^{+}$eram consequenciadas com o desaparecimento de todos os estímulos da tela por $1 \mathrm{~s}$ e o reinício da tentativa, com a reapresentação de todos os estímulos nas mesmas posições. A seleção de cada uma das figuras definidas como $\mathrm{S}^{+}$era consequenciada com o desaparecimento do estímulo selecionado, a movimentação do cenário por cerca de $2 \mathrm{~s}$ até a representação de uma televisão, onde era apresentada a consequência reforçadora programada. A exibição da consequência era sucedida pelo deslocamento inverso e reapresentação da tentativa.

Todos os estímulos eram reapresentados sob o mesmo arranjo anterior à resposta, exceto o estímulo com função de $\mathrm{S}^{+}$previamente selecionado, que não era mais apresentado. A seleção de todas os estímulos definidos como corretos (três a cada tentativa) produzia a movimentação do cenário em profundidade e a apresentação de um novo conjunto de árvores, sobre as quais os mesmos estímulos eram reapresentados em um novo arranjo (tentativa 2 ou 3 ). 


\section{Elementos dos Conjuntos (sn)}

\section{Conjuntos de estímulos} $b$ C $d$

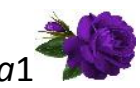
Função na Linha de Base $\mathrm{S}^{+}$ $S^{-}$ $a 2$

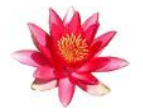<smiles>C1CC2CC3CC1CC2C3</smiles>

c2<smiles>CC=CC</smiles>

$d 2$

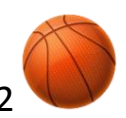

d1

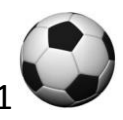
h1 $e$ e1

f

g $g 1$

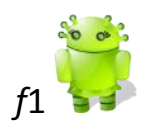

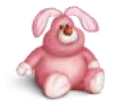

f1

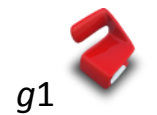

h
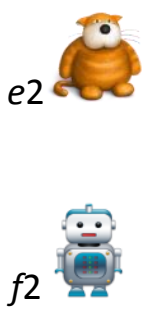

g2

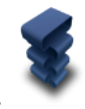

h2
$\mathrm{S}^{-}$

s3

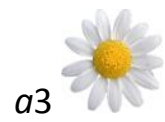

A

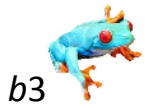

B

c3

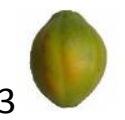

B2

C2

d3

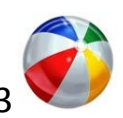

e3

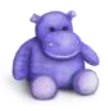

A3

A3

B3

C3

empregados

B1

C1

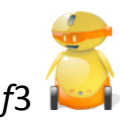

A4

g3

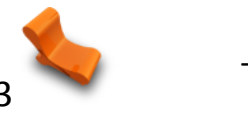

B4

Figura 1. Estímulos empregados ao longo das etapas de ensino das condições A, B e C dos experimentos 1, 2 e 3.

Nas tentativas 2 e 3, os três estímulos do conjunto (sendo três exemplares idênticos de cada elemento) eram reapresentados, com as mesmas funções da tentativa precedente, em um novo arranjo e com tamanhos iguais. A seleção de cada $\mathrm{S}^{+}$produzia as mesmas consequências descritas na tentativa 1 , todavia, a seleção de qualquer um dos seis estímulos negativos produzia o desaparecimento e reapresentação de todos os estímulos após $1 \mathrm{~s}$. O bloco terminava quando todos os estímulos com função de $\mathrm{S}^{+}$fossem selecionados, tentativa a tentativa, e, portanto, o número de acertos por bloco era constante (9). Em contrapartida, o número de erros era variável, uma vez que após a seleção de um $\mathrm{S}^{-}$os estímulos eram reapresentados até a emissão da resposta correta. Na tela de finalização (ver Figura 2) era apresentada a figura de um lagarto em movimento. A resposta de clicar sobre o lagarto produzia a apresentação do vídeo com duração de $8 \mathrm{~s}$ (na Condição A) ou das estrelas com duração de $2 \mathrm{~s}$ (na Condição B). 


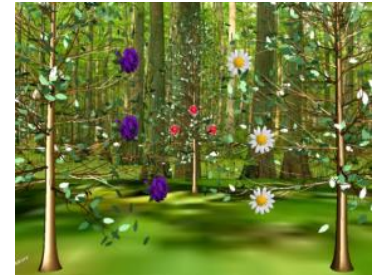

Tentativa 1

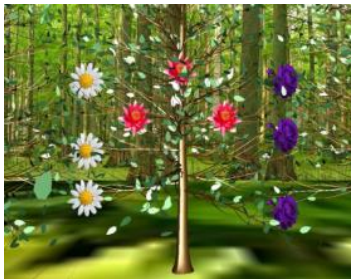

Tentativa 2

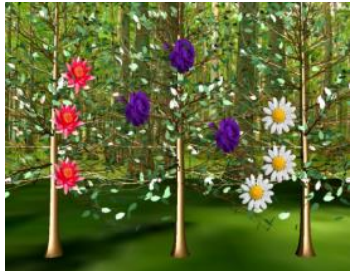

Tentativa 3

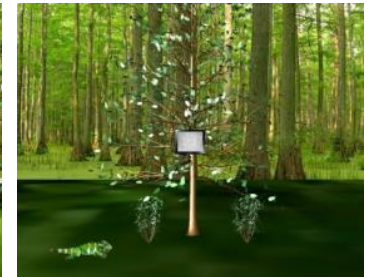

Tela de Finalização

Figura 2. Modelo da tela apresentada nas tentativas 1,2,3 e a Tela de finalização de um bloco de tentativas apresentado em ambiente virtual, com o cenário e os estímulos experimentais sobrepostos. Em cada tentativa três estímulos eram definidos como S+. Cada resposta correta eliminava o estímulo da árvore. A tentativa terminava após a seleção dos três estímulos. Desse modo, eram necessárias nove respostas corretas a cada bloco. Respostas incorretas eram seguidas pelo desaparecimento e reapresentação de todos os estímulos no arranjo anterior à resposta, consequentemente, o número de respostas poderia variar livremente.

\section{Sequência de fases experimentais.}

Nas duas condições, a etapa de ensino foi organizada em seis fases experimentais, realizadas sucessivamente: Discriminação inicial, Reversão 1, Reversão 2, Reversão 3, Reversão 4 e Reversão 5. A cada fase, um dos estímulos do conjunto funcionava como estímulo positivo $\left(\mathrm{S}^{+}\right)$e os outros dois como negativos $\left(\mathrm{S}^{-}\right.$ ). Depois da aquisição da Discriminação inicial, nas fases seguintes era realizada reversão de discriminação, isto é, a função dos estímulos era alterada (o estímulo com função de $\mathrm{S}^{+}$na fase anterior passava a funcionar como $\mathrm{S}^{-}$e um dos $\mathrm{S}^{-}$passava a funcionar como $\mathrm{S}^{+}$, enquanto o outro $\mathrm{S}^{-}$ permanecia com a função de $\mathrm{S}^{-}$). Desse modo, durante a reversão, respostas de seleção do estímulo que exercera função de $\mathrm{S}^{+}$não produziam mais as consequências reforçadoras programadas na fase precedente.

$\mathrm{Na}$ Reversão 1 (R1), o estímulo 2 passava a exercer função de $\mathrm{S}^{+}$; na Reversão 2 (R2), o estímulo 3 era o $\mathrm{S}^{+}$, enquanto nas reversões 3,4 e 5 , os estímulos 1,2 e 3 , respectivamente, exerciam novamente a função de estímulos correlacionados com o reforço. Cada fase era realizada até o alcance do critério de aprendizagem de nove acertos e, no máximo, três erros por bloco e nenhum na terceira tentativa. $\mathrm{O}$ procedimento era concluído após a criança ser exposta às seis fases de cada condição.

As duas condições experimentais (A: vídeos; ou B: estrelas como consequências) eram alternadas ao longo do procedimento. Cada uma seguia sua sequência de seis fases, porém, as fases específicas de cada condição eram sempre realizadas nos blocos de tentativas designados para aquela condição. A alternação dos blocos por tipo de condição era semi-aleatória, conforme uma sequência préestabelecida de até 22 blocos: ABBABABAABBABABABAABBA (delineamento de multielementos; Martin \& Pear, 1999). O procedimento para cada participante, em cada uma das duas condições, era sempre iniciado por um bloco de tentativas da fase de Discriminação inicial (fase 1). Seguindo a sequência planejada de blocos, um participante que atingisse o critério de cada fase, para cada uma das duas condições, com apenas um bloco, faria a Discriminação inicial entre flores (Conjunto $a$ ) no Bloco 1, a primeira reversão no Bloco 4; a segunda reversão no Bloco 6; a terceira no Bloco 8, a quarta no Bloco 9 e a quinta no Bloco 12. Este mesmo participante realizaria a Discriminação inicial entre animais (Conjunto $b$ ) no Bloco 2 e as repetidas reversões nos Blocos 3, 5, 7, 10 e 11, respectivamente. Sempre que um bloco de uma fase (na condição A ou na B) fosse encerrado sem que o critério tivesse sido atingido, aquela fase teria continuidade em um novo bloco, desde que respeitada a sequência de alternância entre os dois tipos de blocos (A ou B).

Assim, por exemplo, no Bloco 1, o participante era exposto a um bloco da fase de Discriminação inicial da Condição A e no Bloco 2, a um bloco da fase de Discriminação inicial da Condição B. No Bloco 3, ele era exposto novamente a um bloco da Condição B (conforme a sequência pré-estabelecida); caso ele tivesse alcançado o critério de aprendizagem da primeira fase no Bloco 2, ele era exposto a um bloco da fase seguinte (Reversão 1); caso ele não tivesse alcançado o critério de aprendizagem, ele era exposto a outro bloco de tentativas da fase de Discriminação inicial dessa condição. No Bloco 4, o participante era exposto a um bloco da Condição A e, do mesmo modo, caso ainda não tivesse aprendido a Discriminação inicial dessa condição, ele era exposto a outro bloco de Discriminação inicial e caso tivesse alcançado o critério, era exposto a um bloco da fase seguinte (Reversão 1). Desse modo, os participantes poderiam realizar um ou mais blocos de tentativas de cada fase experimental e a fase à qual o participante era exposto a cada bloco era determinada pelo alcance do critério de aprendizagem da fase precedente em um bloco imediatamente anterior (da mesma condição experimental).

Os participantes não eram expostos a toda a sequência pré-estabelecida caso aprendessem as discriminações e reversões das duas condições em menos de 22 blocos de tentativas (número máximo previsto pela sequência). Caso o participante alcançasse o critério de aprendizagem nas seis fases de uma das condições e não nas fases da outra condição, ele continuava sendo exposto a blocos de tentativas, conforme a sequência, até o alcance do critério na outra condição. Nesse caso, era possível que os participantes realizassem mais de cinco fases de reversão na condição em que tivessem alcançado o critério de aprendizagem primeiramente. As fases adicionais tinham a mesma estrutura das demais (por exemplo, as fases de Reversão 6 e 7 eram idênticas, respectivamente, às fases de Discriminação inicial e Reversão 1).

\section{RESULTADOS}

Sete dos oito participantes concluíram o experimento e aprenderam as discriminações e reversões 
com ambos os tipos de consequências (vídeos, na Condição A, e estrelas, na Condição B). Duas participantes (P8 e P2) realizaram mais de seis fases experimentais nas Condições A e B, respectivamente (para detalhes, veja o Apêndice 1). Apenas o participante $\mathrm{P} 1$ não concluiu o procedimento, pois depois ter sido exposto tanto a blocos da Condição A, quanto da Condição B, passou a se recusar a frequentar as sessões experimentais diante de convites da experimentadora para ir à sala experimental.

A Figura 3 representa em ordem cronológica, conforme a sequência pré-estabelecida de apresentação das condições, o número de respostas corretas e incorretas emitidas a cada bloco de tentativas nas condições A e B, para cada participante no Experimento 1. Em ambas as condições, todas as crianças apresentaram mais acertos do que erros em todos os blocos, com exceção de P8 no quinto bloco (na Condição B). A maioria das crianças (P1, P2, P3, P4, P5 e P6) apresentou desempenhos similares nas condições A e B: número de erros igual ou inferior a seis desde o primeiro bloco de tentativas, com tendência de diminuição do número de erros emitidos ao longo da exposição aos blocos de ambas as condições. Apenas para P1 não foi possível verificar tendências, pois realizou somente três blocos de tentativas de cada condição. Apenas os participantes P7 e, particularmente, P8 tiveram desempenhos distintos nas condições A e B. Ambos apresentaram tendência de diminuição do número de erros ao longo da exposição à Condição A.

Em contrapartida, na Condição B, P7, nos últimos quatro blocos, e P8, ao longo de toda a exposição, tiveram oscilações do número de erros. Em números absolutos, ambos desempenharam menos erros na Condição A, que na Condição B (P7 desempenou 15 erros em A e 21 erros em B; e P8 desempenhou 14 erros em A e 42 erros em B). Os demais participantes tiveram números aproximados de erros em ambas as condições.

Análises adicionais evidenciaram que a maioria dos participantes (P1, P2, P3, P4, P5 e P6) exibiu erros concentrados nas ocasiões iniciais para as respostas da tentativa 1 dos blocos de tentativas das duas condições ao longo de todo o procedimento. P7 e P8, na Condição A, também apresentaram erros concentrados na primeira tentativa; no entanto, ao longo dos blocos da Condição B, elas tenderam a errar com mais frequência nas tentativas finais ( 2 ou 3 ) dos blocos de tentativas.

\section{DISCUSSÃO}

O objetivo geral do Experimento 1 foi avaliar se a exibição de vídeos de desenhos animados (Condição A), contingente a respostas corretas, produziria efeitos sobre 1) a manutenção dos participantes em situação experimental e 2) o processo de aprendizagem de uma tarefa de discriminação simples em ambiente virtual, em comparação à Condição B, com o uso de animação auditivo-visuais como consequência. Os efeitos das duas condições foram medidos a partir do número de acertos e erros.
O emprego de diferentes consequências parece ter produzido efeitos diversos sobre o processo de aquisição das discriminações, sobretudo, para a participante P8. Para ela, na Condição A (com vídeos) a aprendizagem ocorreu com número menor de erros que na Condição B (com estrelas). O baixo valor reforçador da Condição B para P7 e, sobretudo para P8, também foi sugerido pelo padrão de desempenho nos blocos, com erros concentrados nas tentativas finais. Erros (respostas em $\mathrm{S}^{-}$) concentrados nas tentativas iniciais das fases de reversão podem ser interpretados como comportamentos persistentes produzidos pela história de reforçamento. Em contrapartida, erros concentrados nas tentativas finais das mesmas fases sugerem a diminuição do controle discriminativo exercido pelos estímulos definidos como $\mathrm{S}^{+}$e diminuição do valor reforçador da consequência empregada, já que o responder já havia sido consequenciado nas tentativas anteriores.

Para a maioria dos participantes foram observados poucos erros e não foram observadas diferenças entre os desempenhos nas duas condições. É possível que o pequeno número de erros observados no decorrer da apresentação das duas condições, para a maioria dos participantes (por exemplo, P2, P3, P4, P5 e P6), indique que ambas as condições são viáveis e igualmente eficientes em produzir as aprendizagens discriminativas. Outra possibilidade é que os desempenhos com poucos erros e variação reduzida entre condições tenha sido produzido pela idade e pelo repertório pré-experimental das crianças, de modo que a exposição sucessiva aos blocos não tenha produzido mais efeitos sobre a aprendizagem pois os participantes já possuíam competência no tipo de repertório ensinado.

Adicionalmente, também é possível que estes desempenhos tenham sido influenciados pelo delineamento empregado, que pode ter produzido um efeito de learning-set (Harlow, 1949; Millenson, 1967/1975) entre as duas condições. Assim, a aprendizagem da tarefa no bloco de uma das condições pode ter produzido menor número de erros no bloco da condição subsequente, prejudicando conclusões acerca dos efeitos isolados de cada uma delas. Nessa perspectiva, considerando que em uma sessão as crianças realizavam até três blocos de tentativas e que a sequência de apresentação das condições previa a repetição de uma condição em no máximo dois blocos seguidos, é possível que o delineamento também tenha influenciado a manutenção da maioria das crianças na tarefa. Dessa forma, participar da sessão na Condição $\mathrm{B}$, poderia ser mantido e reforçado por ter acesso a participar em sessão na Condição $A$, resposta mais provável considerando a hipótese de que fosse potencialmente mais reforçadora (Premack, 1959; 1971). Em contrapartida, para o participante P1 é provável que nenhuma das duas condições tenha sido suficientemente reforçadora, já que ele se recusou a retornar à situação experimental após a exposição a alguns blocos das duas condições. 

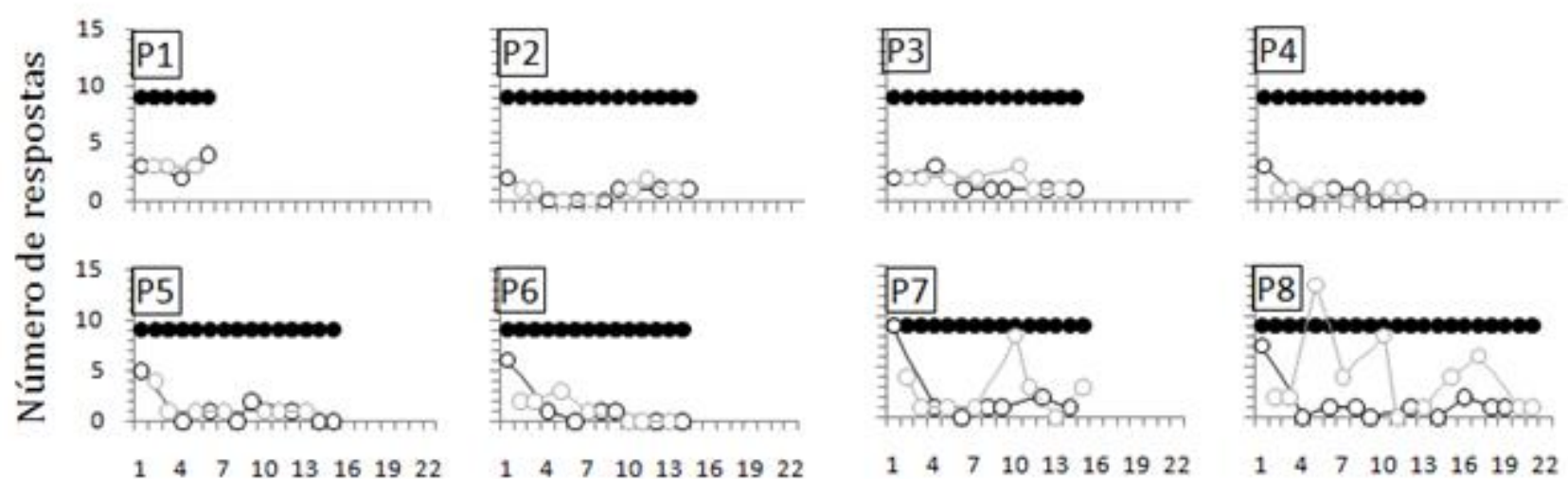

$\begin{array}{llllllll}1 & 4 & 7 & 10 & 13 & 16 & 19 & 22\end{array}$

$\begin{array}{lllllllll}1 & 4 & 7 & 10 & 13 & 16 & 19 & 22\end{array}$

$\begin{array}{llllllll}1 & 4 & 7 & 10 & 13 & 16 & 19 & 22\end{array}$

\section{Blocos sucessivos de tentativas}
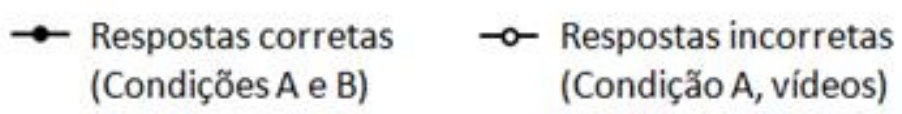

\section{Respostas incorretas (Condição B, estrelas)}

Figura 3. Número de respostas corretas e incorretas nos blocos de tentativas das condições A (com vídeos de desenhos animados) e B (com estrelas coloridas), para cada participante no Experimento 1.

Considerando que a avaliação dos efeitos das consequências específicas sobre o desempenho dos participantes possa ter sido prejudicada pelo delineamento empregado e pelo repertório pré-experimental dos participantes, foi considerada relevante a realização de um estudo adicional com crianças mais jovens e com a programação de um delineamento que isolasse os efeitos de uma condição em relação à outra. Este foi o objetivo do Experimento 2. Além disso, uma limitação do Experimento 1 foi usar apenas dois conjuntos de estímulos (Conjunto $a$ e Conjunto $b$ ), sendo que em cada condição os estímulos eram de uma categoria diferente (flores e animais). Considerando que o tipo de estímulo pudesse ser uma variável crítica para produzir a aprendizagem discriminativa, maior controle experimental teria sido alcançado se fosse realizado um balanceamento dos tipos de estímulos empregados, entre participantes em cada condição (e.g. metade das crianças poderia ter realizado a tarefa na Condição A com flores e a Condição B, com animais; a outra metade das crianças o inverso, Condição A com animais e Condição B com flores). Outra alternativa, seria o emprego de medidas repetidas do efeito das consequências com conjuntos variados de estímulos. Essa foi a estratégia utilizada no Experimento 2. Dessa forma, no segundo experimento foram utilizados oito conjuntos de estímulos diferentes para avaliar os efeitos das consequências, independente dos estímulos antecedentes utilizados.

\section{EXPERIMENTO 2}

O objetivo do Experimento 2 foi favorecer as análises das variáveis independentes (ambiente virtual combinado com diferentes consequências para acertos) sobre as variáveis dependentes (aprendizagem discriminativa e manutenção das crianças em situação experimental) em comparação ao Experimento 1. Para isso, foi empregado um delineamento de medidas repetidas ( $\mathrm{AB} A \mathrm{~B} A \mathrm{BAB}$ ou $\mathrm{BAB} A \mathrm{BABA})$, que, ao invés da apresentação alternada das condições a cada um ou dois blocos de tentativas (delineamento de blocos alternados, Experimento 1), prevê a apresentação de vários blocos consecutivos de uma condição, seguida pela apresentação consecutiva de vários blocos da outra condição e assim, sucessivamente, até a conclusão de quatro etapas de treino de cada condição (ver descrição detalhada em procedimento). Como estratégia para isolar efeitos produzidos pela categoria de estímulos, foram empregados oito conjuntos diferentes de estímulos. Foram recrutados participantes mais jovens.

\section{Participantes}

\section{MÉTODO}

Os participantes foram seis crianças (P9, P10, P11, P12, P13 e P14) com idades entre três anos e sete meses e quatro anos e um mês ( $M=3,9$ anos), em desenvolvimento típico, que não participaram do experimento anterior (ver Tabela 1). De acordo com avaliações por meio do Denver II (Pedromônico et al., 1999), todos tinham desenvolvimento global normal, exceto P10 e P12 que apresentaram atraso, principalmente, na área da linguagem. De acordo com avaliações utilizando o instrumento PPVT-R (Dunn et al., 1981), P9, $\mathrm{P} 10$ e P12 tinham repertório verbal receptivo inferior ao esperado para a idade cronológica e P11, P13 e P14, repertórios superiores aos esperados.

\section{Situação experimental, Equipamentos e Materiais} Experimento 1.

A situação experimental foi a mesma descrita no Experimento 1. 


\section{Estímulos}

Foram empregados os estímulos dos Conjuntos $a$, $c, e$ e $h$, na Condição A, e os estímulos dos Conjuntos $b, d$, $f$ e $h$, na Condição B (ver Figura 1). O uso de diferentes conjuntos de estímulos, associados a uma mesma consequência reforçadora (Condição A ou B), permitiu isolar possíveis efeitos do tipo de antecedente sobre o processo de aprendizagem. Assim, foi possível replicar efeitos produzidos pelas duas condições com mais de um conjunto de estímulos.

\section{Procedimento}

Foi empregado um delineamento de medidas repetidas em que cada sujeito era exposto a blocos sucessivos de uma condição até o alcance do critério de aprendizagem em todas as fases experimentais (Discriminação inicial, Reversão 1, Reversão 2, Reversão 3, Reversão 4 e Reversão 5), seguida pela exposição a toda a sequência de ensino de outra condição e assim repetidamente ao longo de oito etapas de ensino (quatro da Condição A e quatro da Condição B). Foi realizado um balanceamento da ordem de apresentação das condições. Assim, três participantes realizaram sucessivamente as etapas A1, B1, A2, B2, A3, B3, A4 e B4 (delineamento ABABABAB) e outros três participantes as etapas $\mathrm{B} 1, \mathrm{~A} 1, \mathrm{~B} 2, \mathrm{~A} 2, \mathrm{~B} 3, \mathrm{~A} 3, \mathrm{~B} 4$ e A4 (delineamento BABABABA). Conforme o Experimento 1, as condições eram definidas pelas diferentes consequências contingentes às respostas sob controle dos estímulos definidos como $\mathrm{S}^{+}$, sendo a apresentação de desenhos animados característica da Condição A e a apresentação de estrelas coloridas, da Condição B. Cada etapa era composta pelo mesmo número de fases experimentais e a mesma estrutura de blocos de tentativas apresentadas no experimento anteriormente descrito.

Diferente do Experimento 1, respostas em relação ao estímulo representado em tamanho menor na primeira tentativa eram registrados e cada fase (Discriminação inicial ou Reversões) era realizada até o alcance do critério de aprendizagem de nove acertos e no máximo dois erros por bloco de tentativas, sendo um em relação ao estímulo $\mathrm{S}^{-}$representado em tamanho menor na primeira tentativa, outro em qualquer outro estímulo $\mathrm{S}^{-}$da primeira ou segunda tentativa e nenhum na terceira tentativa. No Experimento 1, o critério de aprendizagem era de nove acertos e, no máximo, três erros por bloco e nenhum na terceira tentativa.

Caso o participante apresentasse comportamentos indicativos de dificuldade de aprendizagem, esquiva ou fuga da situação experimental, a exposição da criança à etapa de ensino era interrompida e na sessão seguinte ela era exposta à etapa subsequente. Dificuldade de aprendizagem (D) foi definida pela tendência crescente ou constante do número de erros ao longo de três blocos sucessivos da mesma fase ou mais de cinco erros ao longo de três blocos sucessivos de uma mesma fase. Esquiva da situação experimental (E) foi caracterizada pela recusa em realizar a sessão após ser convidado para ir à sala experimental em três dias sucessivos. Após o alcance do critério definido como de esquiva, a experimentadora informava a criança que se ela fosse à sala experimental poderia jogar um novo "jogo". Foram interpretadas como fuga da tarefa (F), por exemplo, pelo menos três pedidos da criança para interromper o bloco e retornar à sala de aula da creche após iniciar o "jogo" ou a emissão de comportamentos indicativos de desconforto produzido pela situação experimental, como, após olhar para a tela do computador, chorar ou cruzar os braços e deitar a cabeça sobre a mesa por mais de 10 segundos, em uma única sessão ${ }^{1}$. Nesses casos em que a etapa era interrompida, devido a razões éticas, a criança não voltava a ser exposta a blocos daquela etapa e, na sessão seguinte, a criança era exposta a um bloco da etapa subsequente.

\section{RESULTADOS}

Quatro dos seis participantes (P10, P11, P13 e P14) foram expostos a todas as etapas de ensino previstas até o alcance do critério de aprendizagem ou de interrupção das atividades, sendo que P14 foi exposto em duas ocasiões alternadas às etapas $\mathrm{B} 1 \mathrm{e} \mathrm{A} 1$ devido a um erro de procedimento (ver Figura 4). Outros dois participantes, P9 e P12, foram expostos apenas a duas etapas. P9 se esquivou da situação experimental após algumas exposições à etapa $\mathrm{B} 1$ e P12 teve sua participação interrompida durante a etapa A1 por razões externas à situação experimental.

A coluna esquerda da Figura 4 representa, para cada participante, as fases experimentais realizadas com aprendizagem e os comportamentos que geraram a interrupção das atividades (fuga, esquiva ou dificuldade de aprendizagem) na fase seguinte, sem o alcance do critério de aprendizagem. Em todas as etapas da Condição A, as crianças aprenderam as discriminações simples e reversões e se mantiveram na situação experimental, com exceção de P10 em A4 e P11 em A3. P10 se esquivou da situação experimental após a exposição a blocos da etapa A4 e P11 teve dificuldades de aprendizagem da Discriminação inicial em A3. Em todas as etapas da Condição B, as crianças apresentaram comportamentos que levaram à interrupção das atividades, com exceção de P13 que concluiu uma das etapas da condição B (B4) até o critério de aprendizagem.

\footnotetext{
${ }^{1}$ As topografias descritas em categorias pretendem ser funcionais (fuga e esquiva). Todavia, essas funções foram apenas inferidas a partir das topografias e categorias acima descritas, uma vez que não foi realizada análise funcional experimental que demonstrasse que tais topografias e categorias definidas apresentassem as funções de fuga e/ou esquiva.
} 

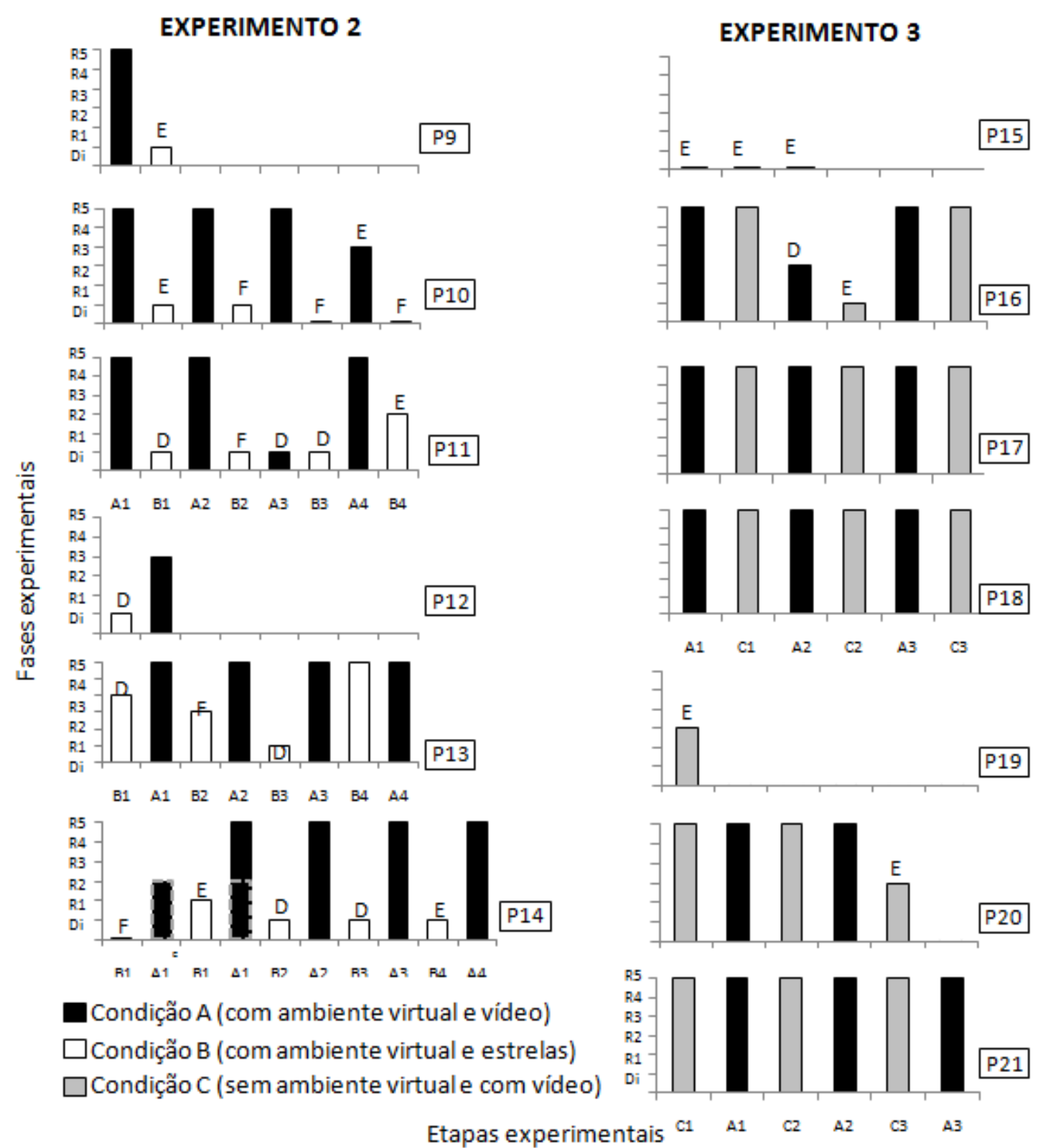

Figura 4. Fases realizadas (DI - Discriminação inicial; e R1, R2, R3, R4 e R5 - Reversões 1, 2, 3, 4 e 5) até o critério de aprendizagem nas etapas das condições A e B, no Experimento 2, e A e C, no Experimento 3, para cada participante. As letras acima das barras indicam que após a última fase representada ocorreram comportamentos indicativos de fuga (F), esquiva (E) ou dificuldade de aprendizagem (D).

A coluna esquerda da Figura 5 apresenta a distribuição do número de respostas corretas (círculos e linha pretos) e incorretas (círculos brancos e linha preta) ao longo dos blocos de tentativas (eixo $\mathrm{Y}$ esquerdo) das etapas de ensino das condições A e B e o número total de erros (círculos brancos e linha cinza pontilhada) apresentados por etapa realizada até o critério de aprendizagem (eixo $\mathrm{Y}$ direito), no Experimento 2. O número de acertos (nove a cada bloco) foi maior que o número de erros, para todos os participantes, ao longo da maioria dos blocos, em ambas as condições. O número de acertos foi inferior a nove (número constante previsto pelo procedimento) somente nos blocos que foram encerrados antes da apresentação da tela de finalização, devido a emissão de comportamentos caracterizados como de fuga da situação experimental.

Em relação ao processo de aprendizagem, a maioria das crianças apresentou tendência decrescente (P9 e P10 em A1; e P11 em A2) ou tendência de manutenção do número de erros próximo a zero (P10 em A2, A3 e A4; P11 em A4; P12 em A1; e P13 e P14 em A1, A2, A3 e A4) ao longo dos blocos de cada uma das etapas da Condição A (ver tendência dos pontos brancos com linha preta a cada etapa). Apenas P11 apresentou tendência de oscilação do número de erros entre zero e cinco ao longo de todo o treino da etapa A1. Também foram observadas tendências de diminuição do número de erros entre as etapas de treino da Condição A (ver tendência da linha cinza pontilhada). 
EXPERIMENTO 2

(Em cenário virtual; consequências vídeos $\mathrm{x}$ estrelas)
EXPERIMENTO 3

(Cenários virtual $\mathrm{x}$ estático; vídeos como consequências)
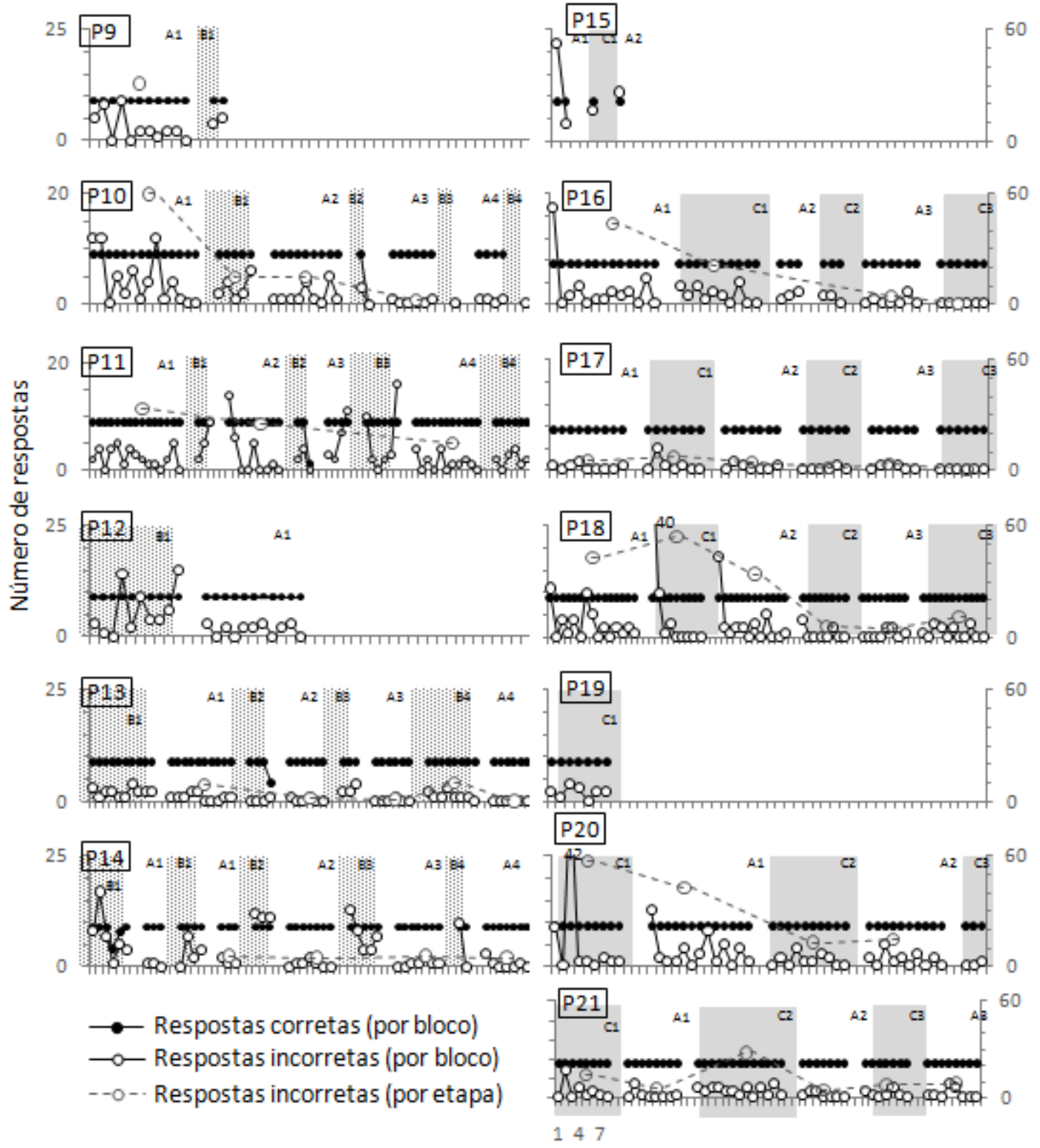

\section{Blocos Sucessivos de Tentativas}

Figura 5. Número de respostas corretas (círculos pretos) e incorretas (círculos brancos) por bloco de tentativas ao longo das etapas de ensino das condições A, com vídeos (fundo branco) e B, com estrelas (fundo pontilhado) no Experimento 2; e das condições A, em cenário virtual (fundo branco) e $\mathrm{C}$, em cenário estático (fundo cinza) no Experimento 3, e número total de erros por etapa realizada até critério de aprendizagem (círculos brancos com linha tracejada), para cada participante.

A verificação dos padrões de tendência de distribuição do número de erros ao longo dos blocos da condição $\mathrm{B}$ foi prejudicada devido à exposição a no máximo dois blocos de tentativas em várias etapas ( $\mathrm{P} 9$ em B1; P10 em B2, B3 e B4; P11 em B2; e P14 em B4) e a não conclusão das etapas até o critério de aprendizagem. Todavia, nas etapas em que foram realizados pelo menos três blocos de tentativas, e que foram encerradas devido ao alcance do critério definido como indicativo de dificuldades de aprendizagem, foram observadas, sobretudo, tendências de elevação do número de erros ao longo dos blocos de uma mesma fase (P11 em B1 e B3; P12 em B1; P13 em B3; e P14 em B3). Nas etapas em que foram realizados pelo menos três blocos de tentativas, e que foram encerradas devido a emissão de comportamentos interpretados como de fuga ou esquiva da situação experimental, foram observadas tendências de oscilação do número de erros entre zero e cinco (P10 em B1; P11 em B4; P13 em B2; e P14 em B1). Para detalhamento acerca do número de erros nas fases de cada etapa ver Apêndice 2. 


\section{DISCUSSÃO}

O objetivo do Experimento 2 foi favorecer a comparação dos efeitos de duas condições experimentais (A e $\mathrm{B}$, diversas em relação à consequência empregada para acertos), sobre a aprendizagem discriminativa e a manutenção de pré-escolares na situação experimental, por meio de um delineamento de medidas repetidas. De modo geral, o delineamento e o recrutamento de participantes mais jovens permitiram a verificação de efeitos sistemáticos das consequências sobre o processo de aprendizagem e manutenção dos participantes em situação experimental. Apesar de ambas as condições terem produzido um número de acertos superior ao número de erros, a exposição alternada às etapas das condições A e B, para a maioria dos participantes, produziu resultados sistemáticos mostrando que a Condição A (vídeos) produziu mais frequentemente a aprendizagem das discriminações e reversões e manteve as crianças em situação experimental, do que a Condição B (animações auditivo-visuais).

Os resultados da Condição A indicam a ocorrência de aprendizagem e efeitos de learning-set (Harlow, 1949; Millenson, 1967/1975) ao longo das reversões e também ao longo das etapas. Estes desempenhos replicam dados da literatura, como o estudo inicial que utilizou um procedimento similar ao do presente experimento (Pereira et al., 2010) e estudos que empregaram desenhos animados como consequência imediata para respostas corretas (e.g., Darcheville, Riviere, \& Wearden, 1993; Klossek, Yu, \& Dickison, 2011; Silva \& de Souza, 2009). Em contrapartida, os resultados obtidos na Condição $B$, como dificuldade de aprendizagem (observada a partir do número de erros) e recusas a ir ou manter-se na situação experimental, divergem da literatura que relata procedimentos que produziram aprendizagem utilizando breves animações auditivo-visuais (e.g., Lionello-DeNolf et al., 2008) ou apenas ambientes virtuais (e.g., Fogel et al., 2010; Monteiro, 2011; Tüzun et al., 2008). Nesses estudos, entretanto, as animações auditivo-visuais exerceram efeito sobre a aprendizagem provavelmente por serem apresentadas em combinação com outras consequências reforçadoras, por exemplo, reforçamento social, fichas e acesso a brincadeira (e.g., Experimento 1, LionelloDeNolf et al., 2008). Além disso, os estudos relatados mantiveram constante um mesmo tipo de consequência, enquanto o presente estudo manipulou dois tipos de consequências, produzindo uma cadeia complexa de comportamentos, durante a qual, em geral, os participantes aprenderam a evitar sistematicamente a condição menos reforçadora, produzindo um acesso mais rápido à condição mais reforçadora (A, com desenhos). Esses comportamentos foram indicativos de que o valor reforçador relativo das consequências (Herrnstein, 1970) foi diferente nas duas condições.

Alguns autores (e.g., Bowman, Piazza, Fisher, Hagopian, \& Kogan, 1997; Egel, 1981) sugerem que o potencial reforçador de um estímulo empregado repetidamente ao longo de um treino tende a diminuir ao longo das tentativas e, em oposição, a apresentação de estímulos variados ao longo do treino mantém o potencial reforçador da tarefa ao longo de um período de tempo superior. Nessa perspectiva, também é possível que a apresentação de trechos diferentes do episódio de desenho animado a cada acerto e a apresentação de episódios diferentes a cada bloco tenham estendido o potencial reforçador da tarefa, enquanto a apresentação repetida da animação de estrelas coloridas tenha tido sua efetividade diminuída ao longo das tentativas de cada etapa de treino. Estudos futuros poderiam comparar, por exemplo, os efeitos de uma condição que empregasse uma mesma animação a cada acerto com uma condição que empregasse animações variadas, porém de durações idênticas.

Em comparação ao Experimento 1, o recrutamento de participantes mais jovens no Experimento 2 favoreceu a observação de um processo de aprendizagem, com diminuição gradativa da proporção de erros em relação a acertos ao longo do procedimento. Todavia, não foram constadas relações entre o desenvolvimento global (Denver II) ou a acurácia do repertório verbal receptivo (PPVT-R) dos participantes e os seus desempenhos nas tarefas discriminativas. De forma geral, os resultados demonstram a viabilidade da utilização de desenhos animados, variados a cada tentativa, como consequência reforçadora em estudos sobre processos básicos de discriminação com crianças pré-escolares. Os resultados obtidos na Condição B sugeriram que o ambiente virtual empregado, por si só, não produziu efeitos sobre a aprendizagem e manutenção das crianças em situação experimental. No entanto, considerou-se relevante a realização de uma investigação para avaliar os efeitos produzidos isoladamente pelo cenário em 3D. Este foi o objetivo do Experimento 3.

\section{EXPERIMENTO 3}

O objetivo do Experimento 3 foi comparar os efeitos do emprego de duas condições experimentais diferentes apenas em relação à apresentação ou à ausência de um fundo tridimensional e dinâmico sob os estímulos discriminativos - sobre o processo de aprendizagem das discriminações e a manutenção das crianças em situação experimental. A consequência, nas duas condições foi a mesma: a apresentação de vídeos de desenhos animados.

\section{MÉTODO}

\section{Participantes}

Os participantes foram outras sete crianças (P15, P16, P17, P18, P19, P20 e P21) com idades entre três anos e quatro meses e três anos e oito meses (M=3,5 anos) com desenvolvimento global normal (Denver II; Pedromônico et al., 1999) e repertório verbal receptivo superior ao esperado para a idade cronológica (PPVT-R; Dunn et al., 1981). Os participantes frequentavam a mesma creche citada nos experimentos anteriores (ver Tabela 1).

\section{Situação experimental, Equipamentos e Materiais}

As sessões experimentais eram realizadas em uma área reservada nas dependências da creche frequentada pelas crianças. A cada sessão era instalado nessa área um 
computador portátil DELL com um monitor de 14 polegadas. A tarefa da criança era a mesma descrita nos experimentos anteriores.

\section{Estímulos}

Os estímulos dos Conjuntos $a, c$ e $e$ foram empregados nas etapas da Condição A e os estímulos dos Conjuntos $b, d$ e $f$ nas etapas da Condição $\mathrm{C}$ (ver Figura 1).

\section{Procedimento}

Foi empregado um delineamento semelhante ao descrito no Experimento 2, em que duas condições experimentais (A e C) eram apresentadas alternadamente ao longo de seis etapas de ensino, três de cada condição. As condições eram definidas pelos cenários sobre os quais os estímulos eram apresentados. A Condição A era idêntica à descrita no Experimento $2 \mathrm{e}$, portanto, os estímulos eram apresentados em ambiente virtual. $\mathrm{Na}$ Condição $\mathrm{C}$, os estímulos eram apresentados sobre um fundo branco uniforme e estático. As consequências contingentes às respostas diante de estímulos com função de $\mathrm{S}^{+}$eram idênticas nas duas condições experimentais (a apresentação de um trecho de desenho animado de escolha da criança). Quatro participantes realizaram as etapas de ensino A1, C1, A2, C2, A3 e C3 (delineamento ACACAC) e outros três, as etapas C1, A1, C2, A2, C3 e A3 (delineamento CACACA). As etapas tinham a mesma sequência de fases, estrutura de blocos e sequência de tentativas descritas no experimento anterior. Os critérios de aprendizagem e para interrupção das tarefas também eram os mesmos descritos no Experimento 2.

\section{RESULTADOS}

Os dados relativos às fases e etapas concluídas pelos participantes no Experimento 3 são apresentados na coluna direita da Figura 4. Dentre os sete participantes, três (P17, P18 e P21) aprenderam as discriminações simples e reversões e se mantiveram em situação experimental em todas as fases das etapas de ensino previstas (as fases experimentais são apresentadas no eixo y e os comportamentos para a interrupção das etapas são representados por uma letra acima de cada barra de cada etapa, para cada participante). Dois participantes (P16 e P20) atingiram o critério de aprendizagem em quatro das seis etapas. P16 teve dificuldades de aprendizagem na etapa A2 e após a exposição a alguns blocos da etapa seguinte, C2, esquivou-se da situação experimental. Ele retornou às sessões e atingiu critério de aprendizagem nas etapas subsequentes, depois de a experimentadora informá-lo que episódios de novos personagens de desenhos animados haviam sido disponibilizados. P20 se recusou a frequentar a situação experimental após a realização de blocos de tentativas da etapa $\mathrm{C} 3$ e não foi exposta aos blocos da última etapa (A3) devido ao encerramento do período letivo. Apenas P15 e P19 não finalizaram nenhuma das etapas, pois se recusaram a frequentar a situação experimental após a exposição a alguns blocos de tentativas. P19 abandonou a situação experimental após a exposição a blocos da etapa C1 e jamais retornou ao procedimento. P15 apresentou respostas sistemáticas de esquiva após a exposição a apenas um bloco das etapas A1, C1 e A2.

A coluna direita da Figura 5 apresenta a distribuição do número de respostas corretas e incorretas ao longo dos blocos de tentativas das etapas de ensino das condições $\mathrm{A}$ e $\mathrm{C}$ e o número total de erros apresentados por etapa concluída até o critério de aprendizagem. Todos os participantes apresentaram número de acertos superior ao número de erros na maioria dos blocos de tentativas e tendência decrescente do número de respostas incorretas ao longo dos blocos de cada etapa, em ambas as condições. Apenas P16 teve tendência crescente do número de erros em blocos de uma mesma fase em A2 e, por isso, teve sua exposição a essa etapa interrompida. A análise do número total de erros em cada etapa de ensino realizada até o critério de aprendizagem evidenciou uma tendência regular de diminuição do número de repostas incorretas ao longo das etapas para os participantes P16, P18, P20 e P21, independente da condição experimental. Entretanto, P21 exibiu aumento do número erros na etapa $\mathrm{C} 2$ em relação às demais etapas, enquanto P17 emitiu número reduzido de erros em todas as etapas de ensino.

\section{DISCUSSÃO}

O Experimento 3 teve como objetivo identificar os efeitos do emprego do ambiente virtual em comparação com um ambiente branco e estático sobre o valor reforçador da tarefa e manutenção das crianças em situação experimental, por meio de duas condições experimentais diferentes apenas em relação ao cenário de apresentação dos estímulos (Condição A, em ambiente virtual; e Condição C, em ambiente branco e estático). As análises indicaram que as duas condições produziram aquisição das discriminações e reversões e padrões de manutenção e/ou esquiva da situação experimental semelhantes em todos os participantes. A maioria das crianças se manteve em situação experimental na maioria das etapas, apresentou mais acertos que erros na maioria dos blocos, exibiu aprendizagem discriminativa e efeitos de learning-set (Harlow, 1949; Millenson, 1967/1975) ao longo das fases e etapas, indicando que, em geral, ambos os procedimentos produziram a aprendizagem nos participantes. Apenas a etapa $\mathrm{C} 1$ produziu um número elevado de erros (40 e 42) em um dos blocos para duas participantes (P18 e P20). É possível que respostas persistentes em relação a um dos estímulos tenham sido selecionadas na história pré-experimental das participantes, já que os estímulos eram familiares.

Para os participantes P15 e P19, as condições não foram suficientes para mantê-los em situação experimental. P15 não se manteve frequentando regularmente a situação após a exposição às etapas de qualquer uma das duas condições, indicando que nenhuma delas produziu acesso a reforçadores para este participante. No caso de P19, observou-se recusa para frequentar a situação experimental logo após a exposição à primeira condição de treino, no caso, à Condição C, indicando que o jogo sem ambiente virtual não apresentou valor reforçador para a criança, apesar de associado ao 
acesso de vídeos de desenhos animados. O fato de P19 não ter sido exposta a nenhuma etapa da Condição A impediu a avaliação do valor reforçador relacionado.

Os resultados obtidos demonstram que a consequência empregada para respostas corretas (vídeos de desenhos animados) foi o aspecto mais determinante da aprendizagem e da manutenção dos participantes em situação experimental, apesar de não ter sido efetivo para todos. O caráter reforçador da consequência empregada também foi sugerido pelo desempenho do participante $\mathrm{P} 16$, cuja motivação em relação às tarefas variou em função do acesso a novos desenhos animados. Para a participante P20, no entanto, a apresentação de respostas de esquiva em uma das etapas finais do procedimento pode indicar a diminuição do potencial reforçador da tarefa. Para essa conclusão, seria necessário que a participante tivesse sido exposta à última etapa do procedimento.

A replicação dos resultados intra e entre alguns participantes demonstra que o emprego do ambiente virtual não produziu sobre a aprendizagem efeitos diferentes da tarefa que empregou o ambiente branco e estático. Estes resultados são divergentes da literatura que relata aprendizagem mais rápida e com maior manutenção dos participantes em situação experimental utilizando procedimentos informatizados em ambientes virtuais (e.g. Fogel et al., 2010; Monteiro et al., 2011; Tüzun et al., 2008). Nesses estudos, provavelmente, outras variáveis, além da presença de tratamentos gráficos em um cenário, exerceram efeitos sobre o comportamento. Neles, além do cenário em três dimensões, havia representações de figuras humanas (avatares) e a oportunidade de emissão de respostas de topografias variadas, em relação a estímulos diferentes, que produziam instantaneamente consequências específicas sobre o ambiente e intrínsecas ao jogo (reforçadores intrínsecos), por exemplo, movimentação do avatar e/ou do objeto manipulado por ele dentro do cenário.

Estudos futuros serão necessários para investigar quais variáveis empregadas nos procedimentos em ambiente virtual e relatadas pela literatura da área são potencialmente reforçadoras para a maioria das crianças. Por exemplo, seria relevante um estudo que manipulasse a consequência reforçadora e comparasse os desempenhos produzidos por um procedimento de discriminação que gerasse reforçadores extrínsecos à seleção do estímulo (como a apresentação de vídeos) e outro procedimento de discriminação que produzisse consequências sobre o ambiente e o estímulo em função da resposta emitida (reforçadores intrínsecos). Seria um exemplo de reforçador intrínseco, considerando a tarefa utilizada nesse estudo, por exemplo, a exibição da animação de um macaco subindo na árvore e coletando o estímulo selecionado. Acredita-se que a identificação dessas variáveis poderia contribuir para favorecer a produção de aprendizagem e a manutenção de crianças em tarefas informatizadas de ensino.

\section{CONSIDERAÇÕES FINAIS}

O conjunto de experimentos descritos no presente artigo indicou a viabilidade do emprego do procedimento informatizado desenvolvido por Brito Neto e colaboradores (2008) para ensinar discriminações simples para crianças pré-escolares. Em todos os experimentos, a tarefa produziu mais acertos que erros na maioria dos blocos para todos os participantes. É possível que características específicas do procedimento, como a apresentação e reapresentação simultânea de vários exemplares idênticos dos estímulos positivos $\left(\mathrm{S}^{+}\right)$e negativos $\left(\mathrm{S}^{-}\right)$a cada tentativa e a exigência de emissão de várias respostas corretas para o encerramento das tentativas, tenham favorecido estes desempenhos. Com o objetivo de investigar metodologias que favoreçam a aprendizagem discriminativa, estudos futuros deverão comparar os desempenhos produzidos pelo procedimento proposto por Brito Neto e colaboradores (2008) com, por exemplo, procedimentos que apresentem simultaneamente apenas um exemplar de cada um dos estímulos discriminativos a cada tentativa.

Os resultados replicados ao longo dos experimentos também evidenciaram que o emprego isolado de vídeos de desenhos animados como consequência imediata para respostas corretas controlou mais frequentemente as aprendizagens (e.g., Darcheville et al., 1993; Klossek et al., 2011; e Silva et al., 2019), em relação ao emprego isolado de breves animações de estrelas coloridas acompanhadas de um som ascendente. Isso indicou que vídeos de desenhos animados podem ser empregados, em tarefas informatizadas, como uma estratégia efetiva para produzir a aprendizagem de crianças nessa faixa etária.

O estudo não produziu evidências de que o emprego isolado do fundo tridimensional e dinâmico tenha produzido efeitos diferenciais sobre a emissão e a distribuição de respostas incorretas e a manutenção das crianças na tarefa. Apesar de o cenário em combinação com vídeos ter produzido a aprendizagem de várias crianças (Condição A), os resultados demonstram que o uso do cenário, isoladamente, sem as consequências adequadas (Condição B), pode não ser suficiente para produzir a aprendizagem e manter a maioria das crianças em situação experimental. Pesquisas futuras na área poderiam investigar em quais condições (ou em combinação com quais variáveis) os ambientes virtuais poderiam produzir os efeitos que têm sido descritos na literatura (e.g., Fogel et al., 2010; Monteiro et al., 2011; Tüzun et al., 2008), entre os quais, favorecer a aprendizagem e a manutenção das crianças em situação experimental.

\section{REFERÊNCIAS}

Belloni, M. L., \& Gomes, N. G. (2008). Infância, mídias e aprendizagem: autodidaxia e colaboração. Educação e Sociedade, 29, 717-746.

Bowman, L. G., Piazza, C. C., Fisher, W., Hagopian, L. P., \& Kogan, J. S. (1997). Assessment of preference for varied versus constant reinforcement. Journal of Applied Behavior Analysis, 30, 451-458.

Brito Neto, C. S., Ribeiro Filho, M. F., \& Galvão, O. F. (2008). Macacos- prego (Cebus apella) resolvem 
problemas de discriminação simples em ambiente virtual. $X$ Symposium of Virtual and Augmented Reality, 10, 359-366.

Burdea, G., \& Coiffet, P. (1994). Virtual reality technology. Nova York: John Wiley \& Sons.

Canovas, D. S., de Souza, D. G., \& Barros, R. S. (2013). Simple successive discrimination and functional class formation in preschool children. The Psychological Record, 63, 1-20.

Catania, A. C. (1999). Aprendizagem: comportamento, linguagem e cognição. Porto Alegre: Artmed. (Publicado originalmente em 1998).

Darcheville, J. C., Riviere, V., \& Wearden, J. H. (1993). Fixed-interval performance and self-control in infants. Journal of the Experimental Analysis of Behavior, 60, 239-254.

Dube, W. V. (1991). Computer software for stimulus control research with Macintosh computers. Experimental Analysis of Human Behavior Bulletin, 9, 28-39.

Dube, W. V., \& Hiris, E. J. (1996). MTS v11.6. Software desenvolvido somente para Pesquisa e Educação. (E. K. Shriver Center for Mental Retardation, Inc).

Dunn, L. M., \& Dunn, L. M. (1981). Peabody Vocabulary Test - Revised. Minesota: American Guidance Service.

Egel, A. L. (1981). Reinforcer variation: Implications for motivating developmentally disabled children. Journal of Applied Behavior Analysis, 14, 345-350.

Fogel, V. A., Miltenberger, R. G., Graves, R., \& Koehler, S. (2010). The effects of exergaming on physical activity among inactive in a physical education classroom. Journal of Applied Behavior Analysis, 43, 591-600.

Garris, R., Ahlers, R., \& Driskell, J. E. (2002). Games, motivation, and learning: A research and practice model. Simulation \& Gaming, 33, 441-467.

Gil, M. S. C. A., Oliveira, T. P., \& McIlvane, W. J. (2011). Conditional discriminations by preverbal children in an identity matching-to-sample task. The Psychological Record, 61, 327-340.

Gil, M. S. C. A., Oliveira, T. P., Sousa, N. M., \& Faleiros, D. A. M. (2006). Variáveis no ensino de discriminação para bebês. Psicologia: Teoria $e$ Pesquisa, 22, 143-152.

Harlow, H. F. (1949). The formation of learning sets. Psychological Review, 56, 51-65.

Herrnstein, R. J. (1970). On the law of effect. Journal of the Experimental Analysis of Behavior, 13, 243266.
Klossek, U., Yu, S., \& Dickinson, A. (2011). Choice and goal-directed behavior in preschool children. Learning \& Behavior, 39, 350-357.

Lionello-DeNolf, K., McIlvane, W. J., Canovas, D. S., de Souza, D. G., \& Barros, R. S. (2008). Reversal learning set and functional equivalence in children with and without autism. The Psychological Record, $58,15-36$.

Martin, G., \& Pear, J. (1999). Behavior modification: What is it and how to do it. New Jersey: Prentice Hall.

Millenson, J. R. (1975). Principles of behavioral analysis. New York: The MacMillian Company. (Publicado originalmente em 1967)

Monteiro, C. B. M. (Org.) (2011) Realidade Virtual na Paralisia Cerebral. São Paulo: Plêiade.

Oliveira, T. P., \& Gil, M. S. C. A. (2008). Condições experimentais facilitadoras para a aprendizagem de discriminação por bebês. Psicologia: Teoria $e$ Pesquisa, 24, 5-18.

Pedromônico, M. R. M., Bargatto, E. L., \& Strobilus, R. (1999). Teste de Triagem Denver II. São Paulo: UNIFESP.

Pereira, V. A., Canovas, D. S., de Souza, D. G., Brito Neto, C. S., \& Galvão, O. F. (2010). Ambientes virtuais como ferramenta para a aprendizagem de discriminação em pré-escolares. Trabalho apresentado como parte da Sessão Coordenada Processos Básicos de Controle de Estímulos IV: Aprendizagem de discriminações em diferentes populações, apresentado na XL Reunião Anual da Sociedade Brasileira de Psicologia. Curitiba, 20 a 23 de outubro, 2010.

Pilgrim, C. (1998). The human subject. In Handbook of research methods in human operant behavior $\left(1^{\mathrm{a}} \mathrm{ed}\right.$., cap. 2). New York, NY: Plenum Press.

Pilgrim, C., Click, R., \& Galizio, M. (2011). A developmental analysis of children's equivalenceclass formation and disruption. Acta de Investigación Psicológica, 1, 55-76.

Postalli, L. M. M., Canovas, D. S., \& de Souza, D. G. (2015). Simple discrimination and reversal learning sets in typically developing young children. The Psychological Record, 65, 411-423.

Premack, D. (1959). Toward empirical behavior laws: I. Positive reinforcement. Psychological Review, 66, 219-233.

Premack, D. (1971). Catching up with common sense or two sides of a generalization: Reinforcement and punishment. In R. Glaser (Ed.), The nature of reinforcement (pp. 121-150). New York: Academic Press. 
Silva, F. T. N., \& de Souza, C. B. A. (2009). Discriminação simples com mudanças sucessivas na função dos estímulos: aprendizagem em bebês. Psicologia: Teoria e Pesquisa, 25 (4), 569-580.

Tüzün, H., Yılmaz-Soylu, M., Karakus, T., Inal, Y., \& Kizılkaya, G. (2008). The effects of computer games on primary school student's achievement and motivation on geography learning. Computer \& Education, 52, 68-77.

Submetido em 23/02/2015. Aceito em 26/05/2015. Publicado em 01/02/2016. 


\section{APÊNDICE 1}

Número de erros e blocos de tentativas (erros/blocos) realizados, até a apresentação da tela de finalização, por fase experimental das etapas de treino, para cada participante do Experimento 1.

\begin{tabular}{|c|c|c|c|c|c|c|c|c|c|}
\hline \multirow[b]{3}{*}{ Etapa } & \multirow[b]{3}{*}{ Fase } & \multicolumn{8}{|c|}{ Número de erros/ Número de blocos de tentativas } \\
\hline & & \multicolumn{8}{|c|}{ Participantes } \\
\hline & & P1 & P2 & P3 & P4 & P5 & P6 & P7 & P8 \\
\hline \multirow[t]{8}{*}{ A } & $\mathrm{Di}$ & $3 / 1$ & $2 / 2$ & $2 / 1$ & $3 / 1$ & $5 / 2$ & $7 / 2$ & $10 / 2$ & $7 / 2$ \\
\hline & R1 & $2 / 1$ & $0 / 1$ & $4 / 2$ & $0 / 1$ & $1 / 1$ & $0 / 1$ & $0 / 1$ & $1 / 1$ \\
\hline & R2 & $4 / 1^{a}$ & $0 / 1$ & $1 / 1$ & $1 / 1$ & $0 / 1$ & $1 / 1$ & $1 / 1$ & $1 / 1$ \\
\hline & R3 & & $1 / 1$ & $1 / 1$ & $1 / 1$ & $2 / 1$ & $1 / 1$ & $1 / 1$ & $0 / 1$ \\
\hline & R4 & & $1 / 1$ & $1 / 1$ & $0 / 1$ & $1 / 2$ & $0 / 1$ & $2 / 1$ & $1 / 1$ \\
\hline & R5 & & $1 / 1$ & $1 / 1$ & $0 / 1$ & $0 / 1$ & $0 / 1$ & $1 / 1$ & $0 / 1$ \\
\hline & R6 & & & & & & & & $3 / 2$ \\
\hline & R7 & & & & & & & & $1 / 1$ \\
\hline \multirow[t]{7}{*}{ B } & $\mathrm{Di}$ & $3 / 1$ & $1 / 1$ & $2 / 1$ & $1 / 1$ & $5 / 2$ & $2 / 1$ & $5 / 2$ & $2 / 1$ \\
\hline & R1 & $3 / 1$ & $1 / 1$ & $2 / 1$ & $1 / 1$ & $1 / 1$ & $2 / 1$ & $1 / 1$ & $2 / 1$ \\
\hline & R2 & $3 / 1$ & $0 / 1$ & $4 / 2$ & $1 / 1$ & $1 / 1$ & $4 / 2$ & $1 / 1$ & $25 / 4$ \\
\hline & R3 & & $0 / 1$ & $3 / 1$ & $0 / 1$ & $1 / 1$ & $0 / 1$ & $11 / 2$ & $1 / 1$ \\
\hline & R4 & & $1 / 1$ & $1 / 1$ & $1 / 1$ & $1 / 1$ & $0 / 1$ & $0 / 1$ & $11 / 3$ \\
\hline & R5 & & $2 / 1$ & $1 / 1$ & $1 / 1$ & $1 / 1$ & $0 / 1$ & $3 / 1$ & $1 / 1$ \\
\hline & R6 & & $1 / 1$ & & & & & & \\
\hline
\end{tabular}

${ }^{a}$ Fase realizada sem o alcance do critério de aprendizagem. 


\section{APÊNDICE 2}

Número de erros e blocos de tentativas (erros/blocos) realizados, até a apresentação da tela de finalização, por fase experimental das etapas de treino, para cada participante do Experimento 2.

\begin{tabular}{|c|c|c|c|c|c|c|c|c|c|}
\hline \multirow{3}{*}{ Participantes } & \multicolumn{9}{|c|}{ Número de erros/ Blocos de tentativas } \\
\hline & \multirow{2}{*}{ Fases } & \multicolumn{8}{|c|}{ Etapas } \\
\hline & & $\mathrm{A} 1$ & B1 & $\mathrm{A} 2$ & B2 & A3 & B3 & A4 & B4 \\
\hline \multirow[t]{6}{*}{ P9 } & $\mathrm{Di}$ & $13 / 3$ & $9 / 2 *$ & & & & & & \\
\hline & R1 & $9 / 2$ & & & & & & & \\
\hline & $\mathrm{R} 2$ & $2 / 1$ & & & & & & & \\
\hline & R3 & $2 / 1$ & & & & & & & \\
\hline & R4 & $3 / 2$ & & & & & & & \\
\hline & R5 & $2 / 2$ & & & & & & & \\
\hline \multirow[t]{6}{*}{ P10 } & $\mathrm{Di}$ & $24 / 3$ & $7 / 3$ & $1 / 1$ & $3 / 1^{*}$ & $1 / 1$ & - & $1 / 1$ & - \\
\hline & $\mathrm{R} 1$ & $14 / 4$ & $8 / 2^{*}$ & $1 / 1$ & & $0 / 1$ & & $1 / 1$ & \\
\hline & $\mathrm{R} 2$ & $17 / 3$ & & $1 / 1$ & & $0 / 1$ & & $0 / 1$ & \\
\hline & R3 & $5 / 2$ & & $1 / 1$ & & $0 / 1$ & & $1 / 1$ & \\
\hline & $\mathrm{R} 4$ & $0 / 1$ & & $5 / 3$ & & $0 / 1$ & & & \\
\hline & R5 & $0 / 1$ & & $6 / 2$ & & $1 / 1$ & & & \\
\hline \multirow[t]{7}{*}{ P11 } & $\mathrm{Di}$ & $6 / 3$ & $16 / 3^{*}$ & $20 / 3$ & $6 / 2 *$ & $23 / 4^{*}$ & $12 / 3$ & $4 / 2$ & $2 / 2$ \\
\hline & $\mathrm{R} 1$ & $10 / 3$ & & $0 / 1$ & & & $21 / 3^{*}$ & $2 / 2$ & $8 / 3$ \\
\hline & $\mathrm{R} 2$ & $10 / 4$ & & $5 / 2$ & & & & $4 / 2$ & $2 / 1$ \\
\hline & R3 & $1 / 1$ & & $0 / 1$ & & & & $1 / 1$ & \\
\hline & R4 & $0 / 1$ & & $1 / 1$ & & & & $1 / 1$ & \\
\hline & R5 & $7 / 3$ & & $0 / 1$ & & & & $3 / 3$ & \\
\hline & & $\mathrm{B} 1$ & $\mathrm{~A} 1$ & B2 & $A 2$ & B3 & A3 & B4 & A4 \\
\hline \multirow[t]{6}{*}{ P12 } & $\mathrm{Di}$ & $4 / 3$ & $3 / 2$ & & & & & & \\
\hline & $\mathrm{R} 1$ & $54 / 7^{*}$ & $2 / 2$ & & & & & & \\
\hline & $\mathrm{R} 2$ & & $7 / 4$ & & & & & & \\
\hline & R3 & & $5 / 3$ & & & & & & \\
\hline & $\mathrm{R} 4$ & & & & & & & & \\
\hline & R5 & & & & & & & & \\
\hline \multirow[t]{6}{*}{ P13 } & $\mathrm{Di}$ & $4 / 2$ & $1 / 1$ & $0 / 1$ & $1 / 1$ & $8 / 3^{*}$ & $0 / 1$ & $2 / 1$ & $0 / 1$ \\
\hline & $\mathrm{R} 1$ & $5 / 3$ & $2 / 2$ & $0 / 1$ & $0 / 1$ & & $0 / 1$ & $1 / 1$ & $0 / 1$ \\
\hline & $\mathrm{R} 2$ & 1/1 & $4 / 3$ & $0 / 1$ & $0 / 1$ & & $0 / 1$ & $1 / 1$ & $0 / 1$ \\
\hline & R3 & $10 / 4^{*}$ & $0 / 1$ & & $1 / 1$ & & $1 / 1$ & $4 / 2$ & $0 / 1$ \\
\hline & R4 & & $0 / 1$ & & $0 / 1$ & & $0 / 1$ & $2 / 2$ & $0 / 1$ \\
\hline & R5 & & $2 / 2$ & & $0 / 1$ & & $0 / 1$ & $0 / 1$ & $0 / 1$ \\
\hline \multirow[t]{6}{*}{ P14 } & $\mathrm{Di}$ & $43 / 7^{a}$ & $1 / 1$ & $34 / 3 *$ & $0 / 1$ & $36 / 5^{*}$ & $0 / 1$ & $10 / 2$ & $4 / 2$ \\
\hline & $\mathrm{R} 1$ & $9 / 2$ & $1 / 1$ & & $1 / 1$ & & $0 / 1$ & & $0 / 1$ \\
\hline & $\mathrm{R} 2$ & $4 / 1^{*}$ & $0 / 1$ & & $1 / 1$ & & $1 / 1$ & & $0 / 1$ \\
\hline & R3 & & $2 / 1$ & & $3 / 2$ & & $1 / 1$ & & $0 / 1$ \\
\hline & $\mathrm{R} 4$ & & $1 / 1$ & & $0 / 1$ & & $3 / 2$ & & $1 / 1$ \\
\hline & R5 & & $1 / 1$ & & $0 / 1$ & & $1 / 1$ & & $0 / 1$ \\
\hline
\end{tabular}

*Fases realizadas sem o alcance do critério de aprendizagem.

${ }^{a} \mathrm{Na}$ fase Di, o participante P14 concluiu três blocos de tentativas; em seguida, ele não concluiu dois blocos consecutivos, pois apresentou comportamento de chorar após emitir algumas respostas na tarefa. Devido a um erro da experimentadora, ele foi exposto a mais dois blocos até aprendizagem. 43 erros é o número total de erros, considerando, inclusive, os dois blocos não concluídos integralmente. 


\section{APÊNDICE 3}

Número de erros e blocos de tentativas (erros/blocos) realizados, até a apresentação da tela de finalização, por fase experimental das etapas de treino, para cada participante do Experimento 3.

\begin{tabular}{|c|c|c|c|c|c|c|c|}
\hline \multirow{3}{*}{ Participantes } & \multicolumn{7}{|c|}{ Número de erros/ Blocos de tentativas } \\
\hline & \multirow{2}{*}{ Fases } & \multicolumn{6}{|c|}{$\begin{array}{c}\text { Etapas } \\
\end{array}$} \\
\hline & & $\mathrm{A} 1$ & $\mathrm{C} 1$ & $\mathrm{~A} 2$ & $\mathrm{C} 2$ & A3 & $\mathrm{C} 3$ \\
\hline \multirow[t]{6}{*}{ P15 } & $\mathrm{Di}$ & $26 / 2^{*}$ & $7 / 1^{*}$ & $11 / 1^{*}$ & & & \\
\hline & $\mathrm{R} 1$ & & & & & & \\
\hline & $\mathrm{R} 2$ & & & & & & \\
\hline & R3 & & & & & & \\
\hline & R4 & & & & & & \\
\hline & R5 & & & & & & \\
\hline \multirow[t]{6}{*}{ P16 } & $\mathrm{Di}$ & $22 / 2$ & $6 / 2$ & $1 / 1$ & $4 / 3$ & $0 / 1$ & $0 / 1$ \\
\hline & R1 & $6 / 3$ & $5 / 2$ & $2 / 1$ & & $1 / 1$ & $0 / 1$ \\
\hline & $\mathrm{R} 2$ & $1 / 1$ & $5 / 2$ & $3 / 1$ & & $0 / 1$ & $0 / 1$ \\
\hline & R3 & $1 / 1$ & $0 / 1$ & & & $0 / 1$ & $0 / 1$ \\
\hline & R4 & $8 / 4$ & $5 / 2$ & & & $0 / 1$ & $0 / 1$ \\
\hline & R5 & $6 / 2$ & $0 / 1$ & & & $3 / 2$ & $0 / 1$ \\
\hline \multirow[t]{6}{*}{ P17 } & $\mathrm{Di}$ & $1 / 2$ & $0 / 1$ & $0 / 1$ & $0 / 1$ & $0 / 1$ & $0 / 1$ \\
\hline & $\mathrm{R} 1$ & $3 / 3$ & $6 / 2$ & $3 / 2$ & $0 / 1$ & $1 / 1$ & $0 / 1$ \\
\hline & $\mathrm{R} 2$ & $0 / 1$ & $0 / 1$ & $0 / 1$ & $0 / 1$ & $1 / 1$ & $0 / 1$ \\
\hline & R3 & $0 / 1$ & $1 / 1$ & $0 / 1$ & $0 / 1$ & $1 / 1$ & $0 / 1$ \\
\hline & $\mathrm{R} 4$ & $0 / 1$ & $0 / 1$ & $0 / 1$ & $1 / 1$ & $0 / 1$ & $0 / 1$ \\
\hline & R5 & $1 / 1$ & $0 / 1$ & $1 / 1$ & $0 / 1$ & $0 / 1$ & $0 / 1$ \\
\hline \multirow[t]{7}{*}{ P18 } & $\mathrm{Di}$ & $11 / 2$ & $51 / 3$ & $21 / 3$ & $4 / 2$ & $0 / 1$ & $1 / 2$ \\
\hline & $\mathrm{R} 1$ & $9 / 4$ & $3 / 2$ & $4 / 3$ & $0 / 1$ & $0 / 1$ & $5 / 3$ \\
\hline & $\mathrm{R} 2$ & $15 / 3$ & $0 / 1$ & $3 / 2$ & $0 / 1$ & $0 / 1$ & $2 / 2$ \\
\hline & R3 & $2 / 2$ & $0 / 1$ & $5 / 2$ & $0 / 1$ & $0 / 1$ & $0 / 1$ \\
\hline & $\mathrm{R} 4$ & $3 / 2$ & $0 / 1$ & $0 / 1$ & $2 / 2$ & $4 / 3$ & $3 / 2$ \\
\hline & $\mathrm{R} 5$ & $3 / 2$ & $0 / 1$ & $1 / 1$ & $0 / 1$ & $1 / 1$ & $0 / 1$ \\
\hline & & $\mathrm{C} 1$ & $\mathrm{~A} 1$ & $\mathrm{C} 2$ & $\mathrm{~A} 2$ & $\mathrm{C} 3$ & A3 \\
\hline \multirow[t]{6}{*}{ P19 } & $\mathrm{Di}$ & $3 / 2$ & & & & & \\
\hline & $\mathrm{R} 1$ & $7 / 3$ & & & & & \\
\hline & $\mathrm{R} 2$ & $4 / 2$ & & & & & \\
\hline & R3 & & & & & & \\
\hline & $\mathrm{R} 4$ & & & & & & \\
\hline & R5 & & & & & & \\
\hline \multirow[t]{6}{*}{ P20 } & $\mathrm{Di}$ & $9 / 2$ & $16 / 3$ & $0 / 1$ & $2 / 2$ & $0 / 1$ & \\
\hline & $\mathrm{R} 1$ & $43 / 2$ & $1 / 1$ & $2 / 2$ & $6 / 2$ & $0 / 1$ & \\
\hline & $\mathrm{R} 2$ & $1 / 1$ & $4 / 2$ & $5 / 2$ & $2 / 1$ & $1 / 1$ & \\
\hline & R3 & $0 / 1$ & $12 / 3$ & $1 / 1$ & $0 / 1$ & & \\
\hline & $\mathrm{R} 4$ & $3 / 2$ & $5 / 2$ & $5 / 3$ & $3 / 2$ & & \\
\hline & R5 & $1 / 1$ & $5 / 2$ & $0 / 1$ & $2 / 2$ & & \\
\hline \multirow[t]{6}{*}{ P21 } & $\mathrm{Di}$ & $0 / 1$ & $0 / 1$ & $5 / 2$ & $1 / 1$ & $2 / 1$ & $1 / 1$ \\
\hline & $\mathrm{R} 1$ & $7 / 2$ & $5 / 3$ & $10 / 4$ & $4 / 2$ & $1 / 1$ & $1 / 1$ \\
\hline & $\mathrm{R} 2$ & $4 / 2$ & $0 / 1$ & $1 / 1$ & $0 / 1$ & $0 / 1$ & $0 / 1$ \\
\hline & R3 & $2 / 1$ & $0 / 1$ & $3 / 2$ & $0 / 1$ & $1 / 1$ & $7 / 3$ \\
\hline & $\mathrm{R} 4$ & $1 / 1$ & $0 / 1$ & $4 / 2$ & $0 / 1$ & $4 / 2$ & $0 / 1$ \\
\hline & $\mathrm{R} 5$ & $0 / 1$ & $1 / 1$ & $5 / 2$ & $0 / 1$ & $0 / 1$ & $0 / 1$ \\
\hline
\end{tabular}

*Fases realizadas sem o alcance do critério de aprendizagem. 